\title{
Secular trends in the epidemiology and outcome of Barrett's oesophagus in Olmsted County, Minnesota
}

M Conio, A J Cameron, Y Romero, C D Branch, C D Schleck, L J Burgart, A R Zinsmeister, L J Melton III, G R Locke III

\begin{abstract}
Background-The incidence of oesophageal adenocarcinoma has increased greatly. Barrett's oesophagus is a known risk factor.
\end{abstract}

Aims-To identify changes in the incidence, prevalence, and outcome of Barrett's oesophagus in a defined population. Subjects-Residents of Olmsted County, Minnesota, with clinically diagnosed Barrett's oesophagus, or oesophageal or oesophagogastric junction adenocarcinoma.

Methods-Cases were identified using the Rochester Epidemiology Project medical records linkage system. Records were reviewed with follow up to 1 January 1998. Results-The incidence of clinically diagnosed Barrett's oesophagus $(>3 \mathrm{~cm})$ increased 28 -fold from $0.37 / 100000$ person years in 1965-69 to $10.5 / 100000$ in 1995-97. Of note, gastroscopic examinations increased 22 -fold in this same time period. The prevalence of diagnosed Barrett's oesophagus increased from 22.6 (95\% confidence interval (CI) 11.7-33.6) per 100000 in 1987 to $82.6 / 100000$ in 1998. The prevalence of short segment Barrett's oesophagus $(<3 \mathrm{~cm})$ in 1998 was 33.4 l 100 000. Patients with Barrett's oesophagus had shorter than expected survival but only one patient with Barrett's oesophagus died from adenocarcinoma. Only four of 64 adenocarcinomas occurred in patients with previously known Barrett's oesophagus.

Conclusions-The incidence and prevalence of clinically diagnosed Barrett's oesophagus have increased in parallel with the increased use of endoscopy. We infer that the true population prevalence of Barrett's oesophagus has not changed greatly, although the incidence of oesophageal adenocarcinoma increased 10-fold. Many adenocarcinomas occurred in patients without a previous diagnosis of Barrett's oesophagus, suggesting that many people with this condition remain undiagnosed in the community.

(Gut 2001;48:304-309)

Keywords: Barrett's oesophagus; oesophageal adenocarcinoma; adenocarcinoma of cardia; epidemiology; gastroscopy; gastro-oesophageal reflux disease
The incidence of adenocarcinoma of the oesophagus and oesophagogastric junction has increased greatly in western countries since about 1970 , especially in white males. ${ }^{1-4}$ The cause of the increase is unknown, although risk factors including smoking, obesity, and a history of gastro-oesophageal reflux disease have been identified, ${ }^{5-9}$ and an inverse relationship to the declining prevalence of Helicobacter pylori has been noted. ${ }^{10}$ The outlook for patients with oesophageal adenocarcinoma is poor; one review showed five year survival of $17 \%$ after surgical resection and $<1 \%$ for unresectable tumours. ${ }^{11}$

Most oesophageal adenocarcinomas arise in a Barrett's oesophagus. ${ }^{12}{ }^{13}$ Adenocarcinoma of the oesophagogastric junction may arise in short or long segments of Barrett's oesophagus. ${ }^{12-14}$ In Barrett's oesophagus, the squamous epithelium of the distal oesophagus, damaged by gastro-oesophageal reflux, is replaced by columnar epithelium. ${ }^{15}{ }^{16}$ In Barrett's oesophagus, there is an estimated $30-52$ times increased risk of developing oesophageal cancer. ${ }^{17}$ Patients with Barrett's oesophagus are usually advised to have periodic endoscopy and biopsy ${ }^{17}{ }^{18}$ for early detection of malignancy.

It is not clear if the increasing incidence of adenocarcinoma is due to a greater prevalence of Barrett's oesophagus, a greater risk of malignant transformation in Barrett's oesophagus, or mechanisms unrelated to Barrett's oesophagus. We sought to address this issue by examining trends in the incidence, prevalence, and outcome of Barrett's oesophagus in a defined population.

\section{Materials and methods}

Population based research is feasible in Olmsted County, Minnesota, because medical care is virtually self contained within the community and there are relatively few providers. The major institution is the Mayo Clinic which has maintained a common medical record with its two affiliated hospitals for over 90 years. Recorded diagnoses and surgical procedures (including endoscopy) are indexed, including diagnoses made for outpatients seen in office or clinic consultations, emergency room visits, or nursing home care, and diagnoses recorded for hospital inpatients, autopsies, or on death certificates. Medical records of other providers serving the local population, especially the Olmsted Medical Center with its affiliated hospital, are also indexed and retrievable. Thus details of the medical care of county residents 
are available through this linked records system, as described elsewhere. ${ }^{19}$

Using this unique database, we identified all Olmsted County residents with a diagnosis of Barrett's oesophagus, or adenocarcinoma of the oesophagus, oesophagogastric junction, or stomach from 1 January 1965 to 1 January 1998. To capture cases of Barrett's oesophagus before the widespread use of the term Barrett's oesophagus as a diagnosis, we retrieved cases indexed as oesophageal ulcer or miscellaneous oesophageal disorder. We also retrieved a group of cases indexed as having had endoscopy and oesophageal biopsy. Thus a total of approximately 900 patient records were identified. Minnesota law forbids review of medical records for research if the patient has declined authorisation. ${ }^{20}$ We were permitted to review $96.5 \%$ of records with a diagnosis of Barrett's oesophagus and $98.4 \%$ of records with a diagnosis of adenocarcinoma. The study was approved by the Mayo Clinic and Olmsted Medical Center institutional review boards.

Barrett's oesophagus was defined as endoscopic visualisation of $3 \mathrm{~cm}$ or more of biopsy proved columnar epithelium in the lower oesophagus. Intestinal metaplasia was confirmed by review of the original histology except in nine old cases, all with columnar epithelium on oesophageal biopsy by pathology report. Dysplasia was defined as previously described. ${ }^{21}$ Short segment Barrett's oesophagus was defined as visualisation of columnar epithelium $<3 \mathrm{~cm}$ in length with intestinal metaplasia. Patients with a biopsy showing intestinal metaplasia, without visible Barrett's oesophagus or short segment Barrett's oesophagus, were excluded. Adenocarcinoma of the oesophagus was defined by histological proof of this neoplasm, with tumour mass centred (as estimated from endoscopic, radiological, and pathological records) $>2 \mathrm{~cm}$ above the oesophagogastric junction. ${ }^{13}$ Adenocarcinoma of the oesophagogastric junction was diagnosed when the tumour centre was estimated to be within $2 \mathrm{~cm}$ of the junction.

Each record was reviewed using a standardised chart abstraction form. The number of upper endoscopic examinations performed on county residents was obtained from the surgical index. The indication for every endoscopic examination in patients with Barrett's oesophagus was reviewed to determine if the procedure was done for symptom evaluation or surveillance only.

Follow up was undertaken to determine the status of all patients on 1 January 1998. Patients were sent a postal questionnaire with subsequent telephone calls for non-responders. Causes of death were identified using the medical record or death certificates. Follow up of patients who left the county was censored when they moved away.

In the calculation of incidence and prevalence of Barrett's oesophagus, patients found to have Barrett's oesophagus at the same time as the diagnosis of an adenocarcinoma were excluded. Incidence and prevalence rates were adjusted to the age and sex distributions of the 1990 US white population. ${ }^{22}$ Survival was esti-

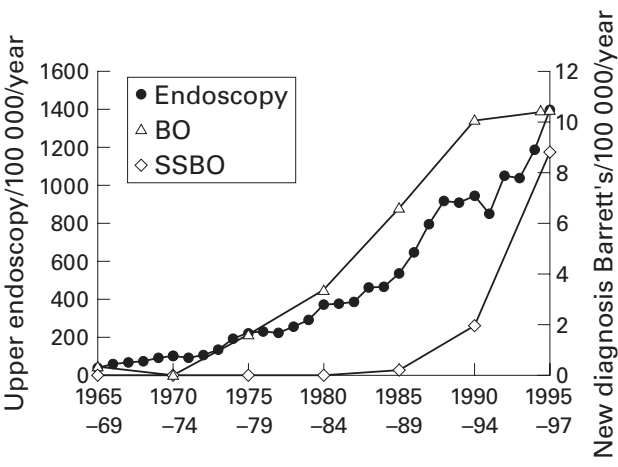

Figure 1 Incidence of new diagnosis of Barrett's oesophagus (BO) and short segment Barrett's oesophagus (SSBO) in Olmsted County residents, 1965-97. Also shown is the annual utilisation rate for upper gastrointestinal endoscopy in the same population.

mated by the Kaplan-Meier method. ${ }^{23} \mathrm{Ob}-$ served survival was compared with the 1990 Minnesota white population using the log rank test. ${ }^{24} \mathrm{~A}$ Poisson regression analysis was used to assess age, sex, and time period effects on crude incidence rates.

\section{Results}

INCIDENCE AND PREVALENCE OF BARRETT'S OESOPHAGUS

The first Barrett's oesophagus $(>3 \mathrm{~cm})$ was found in 1969. By 31 December 1997, this diagnosis had been made in 117 Olmsted County residents ( 86 male, 31 female, mean age at diagnosis 64 years) without cancer at the time Barrett's oesophagus was diagnosed. Mean length of columnar epithelium was 6.7 $\mathrm{cm}$. The first short segment Barrett's oesophagus was recorded in 1989. By 31 December 1997, a diagnosis of short segment Barrett's oesophagus had been made in 37 county residents (22 male, 15 female, mean age 57 years). Mean length of columnar epithelium in short segment Barrett's oesophagus was 1.7 $\mathrm{cm}$.

The incidence trends for Barrett's oesophagus and short segment Barrett's oesophagus are shown in fig 1 . The age and sex adjusted incidence of Barrett's oesophagus increased from 0.37 (95\% confidence interval (CI) $0-1.09)$ per 100000 person years in 1965-69 to 10.5 (95\% CI 6.7-14.2) per 100000 in 1995-97. In 1995-97, the incidence of short segment Barrett's oesophagus was 8.8 cases (95\% CI 5.4-12.2) per 100000 person years.

On 1 January 1998, 77 patients with a diagnosis of Barrett's oesophagus lived in the county, giving an age and sex adjusted prevalence of Barrett's oesophagus of 82.6 (95\% CI 63.8-101.3) per 100000 population. This represented almost a fourfold increase from the prevalence of 22.6 (95\% CI 11.733.6) per 100000 on 1 January 1987. The 1998 prevalence of 147.8 (95\% CI 108.9186.7) per 100000 in males was 4.1 times greater than that in females $(36.0$ (95\% CI 19.0-53.1) per 100 000). On 1 January 1998, 34 patients with short segment Barrett's oesophagus lived in the county. The adjusted prevalence of short segment Barrett's oesophagus was 33.4 (95\% CI 21.0-44.8) per 
100 000; 45.4 (95\% CI 25.3-65.5) in males per 100000 versus 22.7 (95\% CI 10.0-35.4) per 100000 in females.

Upper gastrointestinal endoscopy utilisation in Olmsted County residents increased from 65 examinations per 100000 person years in 1965-69 to 1457 in 1995-97 (fig 1). Altogether, a total of 12907 upper endoscopic examinations were performed in Olmsted County residents (6455 males and 6452 females) between 1965 and 1997.

OUTCOMES IN BARRETT'S OESOPHAGUS

Following the initial diagnostic endoscopy, 117 patients with Barrett's oesophagus had 236 further endoscopic examinations (139 for surveillance, 97 for other indications). For short segment Barrett's oesophagus, 37 patients had 31 surveillance and 12 non-surveillance endoscopic examinations. Only $45 \%$ of Barrett's oesophagus patients had at least one surveillance examination.

DYSPLASIA

Thirty three patients with Barrett's oesophagus had low grade dysplasia on biopsy, one later developing high grade dysplasia. Five Barrett's oesophagus patients had high grade dysplasia, found at the same time as the Barrett's oesophagus in one case, and 2-10 years later in four cases. In the five cases with high grade dysplasia, early adenocarcinoma was subsequently found by further biopsies (one case) or surgical resection (one case). These patients were treated by photodynamic therapy or surgical resection and all five were cancer free at a median 4.5 years later. One patient with short segment Barrett's oesophagus had resection for high grade dysplasia without carcinoma

DEVELOPMENT OF CANCER

Four of 117 patients with Barrett's oesophagus and no cancer at the time of first diagnosis were later found to have adenocarcinoma. Based on US incidence rates, the expected number was 0.043 cases, indicating a 93 (95\% CI 25-237) times increased cancer risk in Barrett's oesophagus. The 117 patients were followed for a mean of 5.0 years, the four cancers occurring at a rate of 1 per 146 patient years. None of 37 short segment Barrett's oesophagus patients developed cancer with a mean follow up of 2.3 years. During 120 patient years of follow up, two patients with Barrett's oesophagus and low grade dysplasia developed adenocarcinoma.

Two of the four adenocarcinomas were detected by surveillance of asymptomatic patients and two were found when endoscopy was performed for symptom evaluation. Three of four were early cancers. The two with preceding high grade dysplasia are described above. Another patient had a $9 \mathrm{~cm}$ Barrett's oesophagus when reflux symptoms were investigated in 1986. He had surveillance endoscopy every two years. In 1996, when asymptomatic and aged 77, biopsy showed adenocarcinoma and high grade dysplasia. A T1 N0 M0 adenocarcinoma was resected and he was well two years later. The fourth patient had a $10 \mathrm{~cm}$ Barrett's oesophagus found when reflux symp-

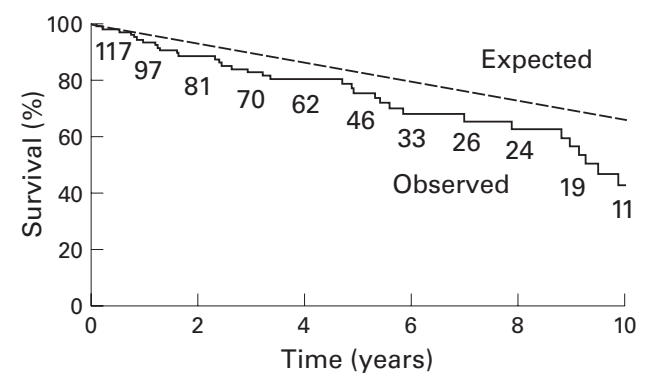

Figure 2 Survival of 117 Olmsted County residents with Barrett's oesophagus ( $3 \mathrm{~cm}$ or longer) was less than expected for the US white population of similar age and sex $(p=0.0006)$. Numbers at risk are shown.

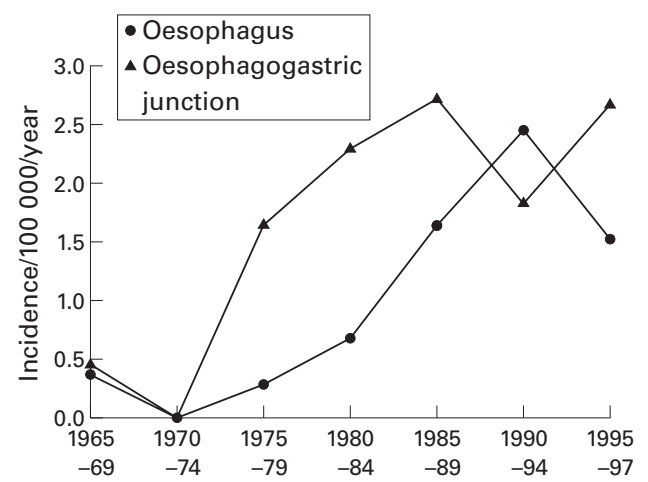

Figure 3 Incidence of adenocarcinoma of the oesophagus and oesophagogastric junction in Olmsted County residents, 1965-97.

toms were investigated. His next endoscopy, performed eight years later for new onset dysphagia, showed unresectable adenocarcinoma.

SURVIVAL IN BARRETT'S OESOPHAGUS

Figure 2 shows survival of 117 patients with Barrett's oesophagus and no cancer at the time of diagnosis. By 1 January 1998, 35 patients had died. Overall survival in Barrett's oesophagus was significantly less than expected $(p=0.0006)$. Only one of $35(3 \%)$ deaths was due to oesophageal cancer. The other 34 patients died of causes unrelated to the oesophagus. Many patients who died were elderly, the mean age in this group being 74 years at the time of diagnosis of Barrett's oesophagus and 78 at death.

INCIDENCE OF ADENOCARCINOMA

From 1965 to 1997,24 cases of oesophageal adenocarcinoma (17 male, seven female, mean age 66 years) and 40 adenocarcinomas of the oesophagogastric junction (35 male, five female, mean age 69 years) were diagnosed in county residents (fig 3). Comparing 1965-74 with 1990-97, the incidence of oesophageal adenocarcinoma increased from 0.2 to 2.0 and junction adenocarcinoma increased from 0.2 to 2.3 per 100000 person years. Although it appears in fig 3 that the incidence rate has levelled off since 1985, regression analysis did not detect a significant departure from linearity $(p>0.1)$.

ADENOCARCINOMA WITH BARRETT'S OESOPHAGUS Only four $(6.3 \%)$ of the 64 patients with adenocarcinoma had Barrett's oesophagus diagnosed $>1$ year before the cancer was found. 
These are described above. A further 17 patients had Barrett's oesophagus found at the same time as the cancer (13 with Barrett's oesophagus, one with short segment Barrett's oesophagus, and three with Barrett's oesophagus of unrecorded length). Overall, 14 of 24 $(58 \%)$ patients with adenocarcinoma of the oesophagus had coexisting Barrett's oesophagus. Of 40 patients with adenocarcinoma of the oesophagogastric junction, three had Barrett's oesophagus, one had short segment Barrett's oesophagus, and three had Barrett's oesophagus of uncertain length.

\section{Discussion}

The increasing incidence of adenocarcinoma of the oesophagus and oesophagogastric junction $^{1-4}$ in the 1970 s and 1980s surpassed that of any other cancer in the USA. ${ }^{1}$ We found an approximately 10 -fold increase in adenocarcinoma in both locations over an interval of 25 years. In absolute numbers these cancers are still uncommon, the 1990-1997 Olmsted County annual incidence being 4.3 cases per 100000 for both sites combined.

Most oesophageal and some junction adenocarcinomas arise in Barrett's oesophagus. We found that both the incidence of adenocarcinoma and prevalence of Barrett's oesophagus showed a male:female ratio of about $4: 1$. The incidence of adenocarcinoma in our Barrett's oesophagus patients was 1 per 146 patient years of follow up, comparable with 1 per $180,{ }^{25}$ 1 per $184,{ }^{26}$ and 1 per $222^{27}$ patient years in recent reports (excluding cases of short segment Barrett's oesophagus).

The rate of new diagnosis of Barrett's oesophagus increased 28-fold over the years of our study from 0.37 to 10.5 cases per 100000 person years. The increased diagnosis rate of Barrett's oesophagus was similar to the 22 -fold increased utilisation rate of endoscopy over the same years. Prach and colleagues ${ }^{28}$ in Scotland found 1.4 Barrett's oesophagus cases per 1000 endoscopies in 1980-1981, with a remarkable increase to 42.7 per 1000 endoscopies 12 years later. These authors concluded that a true increase in the prevalence of Barrett's oesophagus had occurred. In contrast, we found a new Barrett's oesophagus in only $0.75 \%$ of endoscopies performed in 1995-7 (see fig 1). We believe that an increased detection rate explains most of the increase in diagnosed cases in our county. We do not know why our results differ from those of Prach et al but patient selection or population differences may be responsible. Supporting our suggestion that the prevalence of Barrett's oesophagus may have changed little in recent decades, we note that Allison and Johnstone ${ }^{29}$ found Barrett's oesophagus in 11 of 115 patients with strictures seen in Leeds in 1951-3. Naef and Savary ${ }^{30}$ in Switzerland found Barrett's oesophagus in $1.25 \%$ of 4950 endoscopies from 1963-71. These historical data are similar to the present findings. It seems unlikely that the true prevalence of Barrett's oesophagus has increased 10-fold as has the incidence of adenocarcinoma of the oesophagus and oesophagogastric junction. Barrett's oesoph- agus is caused by gastro-oesophageal reflux ${ }^{15}$ but the prevalence of reflux symptoms may also be unchanged. Weekly or more frequent heartburn was reported in $21 \%$ of adults in $1976^{31}$ and in $19.8 \%$ in Olmsted County in $1997 .{ }^{32}$

The evidence suggests that Barrett's oesophagus is under diagnosed in the general population. In prospective studies of subjects with frequent (at least weekly) reflux symptoms, Barrett's oesophagus was found in 11-12\%.33 34 These earlier studies included some patients without intestinal metaplasia, and we believe the prevalence of Barrett's oesophagus in reflux subjects may be nearer 5\%. ${ }^{35}$ If approximately $20 \%$ of adults have frequent reflux symptoms $^{3132}$ and $5 \%$ of these have Barrett's oesophagus, then about one in 100 adults may have Barrett's oesophagus. Barrett's oesophagus is more prevalent in older subjects, but even so, this estimate of the "true" prevalence is much greater than the clinically diagnosed prevalence of 1 in 1210 (82.6 per100 000) found in our study.

In a 1987 autopsy study, we estimated the "true" population prevalence of Barrett's to be 376 per $100000 . .^{36}$ The clinically diagnosed prevalence of Barrett's oesophagus in our county is now 82.6 per 100000 , and if the true prevalence has not changed, we may now have diagnosed approximately one in five of the Barrett's oesophagus cases in the population.

Of our 64 patients with adenocarcinoma, 21 had Barrett's oesophagus or short segment Barrett's oesophagus. Only four of 21 had Barrett's oesophagus found $>1$ year before the cancer; in 17 cases Barrett's oesophagus was found at the same time as the cancer. These findings are similar to other reports. For example, Lagergren and colleagues ${ }^{8}$ found Barrett's oesophagus at the time of cancer diagnosis in $62 \%$ of 189 cases of oesophageal adenocarcinoma. Barrett's oesophagus had apparently not been recognised previously. In contrast, Chow and colleagues ${ }^{5}$ found that only $5 \%$ of 196 patients with adenocarcinoma of the oesophagus or cardia had a previously diagnosed Barrett's oesophagus. We believe that many subjects with Barrett's oesophagus remain undiagnosed unless they develop cancer. It follows that surveillance and early treatment of malignancy in known cases of Barrett's oesophagus will have limited impact on the population death rate from oesophageal cancer.

Surveillance in Barrett's oesophagus was endorsed by the American College of Gastroenterology. ${ }^{18}$ In our 117 Barrett's oesophagus patients, 139 surveillance endoscopic examinations detected two early adenocarcinomas and two cases of high grade dysplasia. These patients had resection or photodynamic treatment and remained well, hence cancer deaths may have been prevented by surveillance. Survival is greater when adenocarcinomas are resected early ${ }^{37}$ although this effect may be exaggerated by lead time and length bias, ${ }^{39}$ and oesophagectomy has a mortality rate of $3-17 \%$, lowest in hospitals where the operation is performed more often. ${ }^{40}$ Surveillance in Barrett's oesophagus may be beneficial as shown in a decision analysis study ${ }^{11}{ }^{41}$; however, another 
group concluded that surveillance was not helpful based on a non-surveyed experience. ${ }^{25}$ Survival of our Barrett's oesophagus patients was less than the general population but only one of our 35 patients with Barrett's oesophagus and no cancer initially died later from oesophageal adenocarcinoma. The reason for this worsened survival is not clear. Possibly, patients with pre-existing illness already seeing a physician are more likely to have endoscopy and to have a Barrett's oesophagus found than other members of the population.

We have not used endoscopy to screen our general population for Barrett's oesophagus because gastro-oesophageal reflux disease is so common. Screening all those with reflux symptoms would still miss the estimated $40 \%$ of patients with adenocarcinoma and Barrett's oesophagus who do not have chronic reflux symptoms. $^{37} 3842$

Junction adenocarcinomas may arise in short segment Barrett's oesophagus. ${ }^{12-14}$ We defined short segment Barrett's oesophagus by visible short tongues or segments $(<3 \mathrm{~cm})$ of columnar mucosa in the oesophagus with intestinal metaplasia on biopsy. This definition ${ }^{43}$ distinguishes short segment Barrett's oesophagus from intestinal metaplasia found just below a normally located squamocolumnar junction which is present in about $15 \%$ of patients having endoscopy if biopsies are taken. ${ }^{44-46}$ It is unknown if such intestinal metaplasia of the cardia carries any increased cancer risk; we did not address this condition in our study.

We attribute the increased detection rate of short segment Barrett's oesophagus after 1989 to awareness of this condition. Previously, short lengths of columnar epithelium were not recorded as Barrett's oesophagus. The risk of cancer in short segment Barrett's oesophagus is not clear. In one report $\mathrm{t}^{27}$ one case developed in 223 patient years of follow up. We found short segment Barrett's oesophagus with adenocarcinoma in one case and with high grade dysplasia in another.

In summary, we have shown that the incidence and prevalence of clinically diagnosed Barrett's oesophagus has increased and we provide the first population based data on the prevalence of short segment Barrett's oesophagus. The majority of subjects with Barrett's oesophagus are not diagnosed or having surveillance. The true population prevalence of Barrett's oesophagus may not have increased since 1965. The reason for the increased incidence of adenocarcinoma of the oesophagus and oesophagogastric junction remains unclear. Changed environmental factors might promote the development of adenocarcinoma in Barrett's oesophagus rather than promote the development of Barrett's oesophagus.

This work was supported by the Mayo Foundation and grant AR 30582 from the National Institutes of Health, US Public Health Service.

1 Blot WJ, Devesa SS, Kneller RW, et al. Rising incidence of adenocarcinoma of the esophagus and gastric cardia. adenocarcinoma of the

2 Pera M, Cameron AJ, Trastek VF, et al. Increasing incidence of adenocarcinoma of the esophagus and esophagogastric junction. Gastroenterology 1993;104:510-13.
3 Devesa SS, Blot WJ, Fraumeni JF. Changing patterns in the ncidence of esophageal and gastric carcinoma in the United States. Cancer 1998;83:2049-53.

4 Bytzer P, Christensen PB, Damkier P, et al. Adenocarcinoma of the esophagus and Barrett's esophagus: a populationbased study. Am f Gastroenterol 1999;94:86-91.

5 Chow WC, Finkle WD, McLaughlin JK, et al. The relation of gastroesophageal reflux disease and its treatment to adenocarcinomas of the esophagus and gastric cardia. fAMA 1995;274:474-7.

6 Chow WH, Blot WJ, Vaughan WJ, et al. Body mass index and risk of adenocarcinomas of the esophagus and gastric cardia. $\mathcal{F}$ Natl Cancer Inst 1998;90:150-5.

7 Gammon MD, Schoenberg JB, Ahsan H, et al. Tobacco, alcohol and socioeconomic status and adenocarcinoma of the esophagus and gastric cardia. I Natl Cancer Inst the esophagus and

8 Lagergren J, Bergstrom R, Lindgren A, et al. Symptomatic gastroesophageal reflux as a risk factor for esophageal adenocarcinoma. N Engl f Med 1999;340:825-31.

9 Lagergren J, Bergstrom R, Nyren O. Association between body mass and adenocarcinoma of the esophagus and gastric cardia. Ann Intern Med 1999;130:883-90.

10 Blaser MJ. Hypothesis: the changing relationships of Helicobacter pylori and humans: implications for health and disease. F Infect Dis 1999;179:1523-30.

11 Provenzale D, Kemp AJ, Arora S, et al. A guide for surveilProvenzale $\mathrm{D}$, Kemp AJ, Arora S, et al. A guide for surveil-
lance of patients with Barrett's esophagus. Am $\mathcal{f}$ Gastroenterol 1994;89:670-9.

12 Hamilton SR, Smith RRL, Cameron JL. Prevalence and characteristics of Barrett esophagus in patients with adenocarcinoma of the esophagus or esophagogastric junction. Hum Pathol 1988;19:942-8.

13 Cameron AJ, Lomboy CT, Pera M, et al. Adenocarcinoma of the esophagogastric junction and Barrett's esophagus. Gastroenterology 1995;109:1541-6.

14 Schnell TG, Sontag SJ, Chejfec G. Adenocarcinomas arising in tongues or short segments of Barrett's esophagus. Dig Dis Sci 1992;37:137-43.

15 Spechler SJ, Goyal RK. Barrett's esophagus. N Engl f Med 1986;315:362-71.

16 Weinstein W, Ippoliti AF. The diagnosis of Barrett's esophagus: goblets, goblets, goblets. Gastrointest Endosc 1996;44:91-5.

17 Tytgat GNJ. Does endoscopic surveillance in esophageal columnar metaplasia have any real value? Endoscopy 1995; 27:19-26.

18 Sampliner RE, and the Practice Parameters Committee of the American College of Gastroenterology. Practice guidelines on the diagnosis, surveillance and therapy of Barrett's esophagus. Am 7 Gastroenterol 1998;93:1028-32.

19 Melton LJ III. History of the Rochester Epidemiology Project. Mayo Clin Proc 1996;71:266-74.

20 Melton LJ III.The threat to medical-records research. $N$ Engl f Med 1997;337:1466-70.

21 Cameron AJ, Carpenter HA. Barrett's esophagus, highgrade dysplasia and early adenocarcinoma: a pathologic study. Am f Gastroenterol 1997;92:586-91.

22 Bergstralh EJ, Offord KP, Chu CP, et al. Calculating incidence, prevalence and mortality rates for Olmsted County, Minnesota: an update. Technical report series No. 49, Section of Biostatics, Mayo Clinic, Rochester, MN, April 1992.

23 Kaplan EL, Meier P. Non-parametric estimation from incomplete observations. F Am Stat Assoc 1958;53:457-61.

24 Kalbfleisch JD, Prentice RL. The statistical analysis of failure time data. New York: John Wiley and Sons, 1980:1-321.

25 Van der Burgh A, Dees J, Hop WCJ, et al. Oesophageal cancer is an uncommon cause of death in patients with Ber is an uncommon cause of death

26 Drewitz DJ, Sampliner RE, Garewal HS. The incidence of adenocarcinoma in Barrett's esophagus: a prospective study of 170 patients followed 4.8 years. Am $\mathcal{F}$ Gastroenterol 1997;92:212-15.

27 O'Connor JB, Falk GW, Richter JB. The incidence of adenocarcinoma and dysplasia in Barrett's esophagus. Am f Gastroenterol 1999;94:2037-42.

28 Prach AT, MacDonald TA, Hopwood DA, et al. Increasing incidence of Barrett's oesophagus: education, enthusiasm or epidemiology? Lancet 1997;350:933.

29 Allison PR, Johnstone AS. Oesophagus lined with gastric mucous membrane. Thorax 1953;8:87-93.

30 Naef AP, Savary M. Conservative operations for peptic esophagitis with stenosis in columnar-lined lower esophaesophagitis with stenosis in columnar-lined
gus. Ann Thoracic Surg 1972;13:543-51.

31 Nebel OT, Fornes MF, Castell DO. Symptomatic gastroesophageal reflux: incidence and precipitating factors. Dig Dis Sci 1976;21:953-6.

32 Locke GR III, Talley NJ, Fett SL, et al. Prevalence and clinical spectrum of gastroesophageal reflux: a populationbased study in Olmsted County, Minnesota. Gastroenterology 1997;112:1448-56.

33 Winters C, Spurling TJ, Chobanian SJ, et al. Barrett's esophagus. A prevalent, occult complication of gastroesophageal reflux disease. Gastroenterology 1987;92:11824.

34 Mann NS, Tsai MF, Nair PK. Barrett's esophagus in patients with symptomatic reflux esophagitis. Am $\mathcal{F}$ Gastroenterol 1989;84:1494-6.

35 Romero Y, Cameron AJ, Hardtke CL, et al. Barrett's esophagus, a familial disorder? Gastroenterology 2000;118:A222.

36 Cameron AJ, Zinsmeister AR, Ballard DJ, et al. Prevalence of columnar-lined (Barrett's) esophagus. Comparison of 
population-based clinical and autopsy findings. Gastroenterology 1990;99:918-22.

Williamson WA, Ellis FH, Gibb SP, et al. Barrett's esophagus. Prevalence and incidence of adenocarcinoma. Arch Intern Med 1991;151:2212-16.

38 Menke-Pluymers MBE, Schoute NW, Mulder AH, et al. Outcome of surgical treatment of adenocarcinoma in Barrett's oesophagus. Gut 1992;33:1454-8.

39 Black WC, Welch HG. Advances in diagnostic imaging and overestimations of disease prevalence and the benefits of therapy. $N$ Engl f Med 1993;328:1237-43.

40 Begg CB, Cramer LD, Hoskins WJ, et al. Impact of hospital volume on operative mortality for major cancer surgery. fAMA 1998;280:1747-51.

41 Provenzale D, Schmitt C, Wong JB. Barrett's esophagus: a new look at surveillance based on emerging estimates of cancer risk. Am $\mathcal{F}$ Gastroenterol 1999;94:2043-53.

42 Van Sandick JW, Van Lanschot JJB, Kuiken BW, et al. Impact of endoscopic biopsy surveillance of Barrett's oesophagus on patholological stage and clinical outcome of Barrett's carcinoma. Gut 1998;43:216-22.

43 Sharma P, Morales TG, Sampliner RE. Short segment Barrett's esophagus - the need for standardization of the definition and of endoscopic criteria. Am f Gastroenterol 1998; 93:1033-6.

44 Spechler SJ, Zeroogian JM, Wang $\mathrm{HH}$, et al. The frequency of specialized intestinal metaplasia at the squamocolumnar junction varies with the extent of columnar epithelium lining the esophagus. Gastroenterology 1995;108: A224.

45 Trudgill NJ, Suvarna SK, Kapur KC, et al. Intestinal metaplasia at the squamocolumnar junction in patients attending for diagnostic gastroscopy. Gut 1997;41:585-9.

46 Voutilainen M, Farkkila M, Juhola M, et al. Specialized columnar epithelium of the esophagogastric junction: prevalence and associations. Am fF Gastroenterol 1999;94:

prevalence 